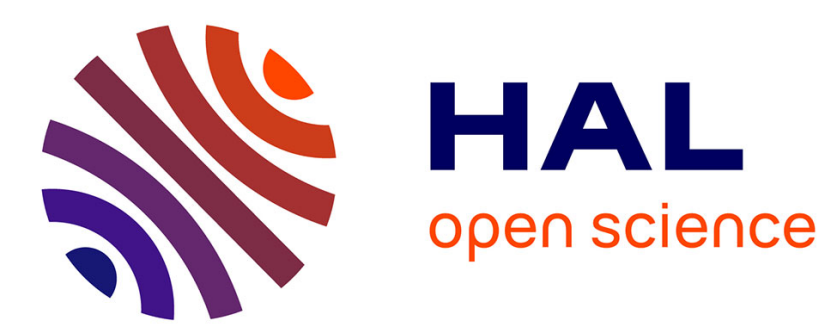

\title{
Rheology of cohesive powders in a pilot scale planetary blender
}

Leonard Legoix, Cendrine Gatumel, Mathieu Milhé, Henri Berthiaux

\section{To cite this version:}

Leonard Legoix, Cendrine Gatumel, Mathieu Milhé, Henri Berthiaux. Rheology of cohesive powders in a pilot scale planetary blender. Powder Technology, 2017, 305, p. 609-619. 10.1016/j.powtec.2016.09.021 . hal-01619258

\section{HAL Id: hal-01619258 \\ https://hal.science/hal-01619258}

Submitted on 7 Nov 2018

HAL is a multi-disciplinary open access archive for the deposit and dissemination of scientific research documents, whether they are published or not. The documents may come from teaching and research institutions in France or abroad, or from public or private research centers.
L'archive ouverte pluridisciplinaire HAL, est destinée au dépôt et à la diffusion de documents scientifiques de niveau recherche, publiés ou non, émanant des établissements d'enseignement et de recherche français ou étrangers, des laboratoires publics ou privés. 


\title{
Rheology of cohesive powders in a pilot scale planetary blender
}

\author{
Léonard Legoix, Cendrine Gatumel, Mathieu Milhe, Henri Berthiaux * \\ Université de Toulouse, Centre RAPSODEE, CNRS UMR 5302, Ecole des Mines d'Albi, Campus Jarlard, 81013 Albi Cedex 09, France
}

Keywords:

Powder mixing

Rheology of mixtures

Power number

Froude number

\begin{abstract}
A B S T R A C T
Powder agitation experiments in a bladed planetary mixer have been performed with the objective of establishing correlations based on dimensionless numbers. Powders of different kind have been studied: free flowing (semolina) and cohesive (lactose, talc and milled sand). Mixtures of free flowing and cohesive powders have also been studied to get a more complete range of powders of different properties. It has been observed that the gyration motion plays an important role in the power consumption of cohesive powders. The relation between a modified power number $\left(N_{p M}=P / \rho_{b} u_{c h}^{3} d_{s}^{2}\right)$ and a modified Froude number $\left(F r_{M}=u_{c h}^{2} / g d_{s}\right)$ used in several previous publications is adapted and shown to depend on powder cohesion. These dimensionless numbers are built on the basis of a characteristic speed $u_{c h}$, a characteristic length $d_{s}$, the bulk density $\rho_{b}$ and the power consumption $P$. The filling ratio $f$ is also taken in account. For a free flowing powder, of cohesion smaller than $0.3 \mathrm{kPa}, N_{p M}=a(f) \cdot F_{r M}^{-1}$ while for a more cohesive powder, of cohesion higher than $0.6 \mathrm{kPa}$ the correlation $N_{p M}=6 \cdot F_{r M}^{b(f)}$ is more appropriate. For both equations, $a$ and $b$ are powder-dependent parameters. Their linear dependency on the filling ratio of the blender has been established.
\end{abstract}

\section{Introduction}

Powder mixing is an important unit operation for the manufacture of several products in many industries, like tablets in the pharmaceutical industry or fuel pellets in the nuclear industry. The goal is to blend different powders having intrinsic properties that may not work together. In the pharmaceutical industry for example, an active pharmaceutical ingredient (API) is mixed with excipients to enable the drug to be manufactured properly and be handled by patients. The challenge in powder mixing is to provide homogeneous mixtures at the wanted scale, knowing that powders can segregate during and after the operation.

Powders can be divided into two groups, according to their flow behavior: free flowing or cohesive. The first group represents powders that can flow easily under gravity, the grains being able to move almost individually. At the opposite, cohesive powders can be defined as particulate systems for which attraction forces are stronger than gravity. These forces can be surface tension of a free interstitial liquid, electrical double layers, Van Der Waals forces and local joining of particles due to compaction. Concerning dry powders, Van Der Waals forces are the most important cause of cohesion, typically when the particle size is smaller than $100 \mu \mathrm{m}$ [1]. There is an increasing interest in manufacturing fine powders. In particular, size reduction is known to enhance some properties like bioavailability for APIs, since poorly aqueous soluble drugs are more readily bioavailable when administrated in a form of

* Corresponding author.

E-mail address: henri.berthiaux@mines-albi.fr (H. Berthiaux). larger surface area [2]. However fine powders are also known for their reduced flowability which is the source of many issues in industries like waste and maintenance problems [3], or increased risks of dust explosions [4]. If cohesive powders are not subjected to problems of demixing by segregation like free flowing powders, understanding and modeling their flow is still a scientific issue. Previous studies evidenced that these powders are characterized by a history-dependent flow, a strong effect of dilatation, a non-periodic avalanche frequency of variable size [5]. Effects of cohesion were not well understood in relation to powder mixing during the 1960s [6]. While the uses of cohesive powder is wider nowadays, this still holds true, even in simple devices like shear cells [7].

For powder blending, different kinds of technologies are available depending on the amount of mixture needed and on powder's properties. Continuous mixing will be preferred for high powder production but batch mixing is still used because of its reliability to monitor the manufacturing step by step. To mix cohesive powders, blenders designed to apply high shear on the mixture are advised since they can break agglomerates of particles, but the stress should not be too significant because of the risk of particle breakage. To mix these powders, convective blenders incorporating an impeller motion inside the tank seem more appropriate than tumbling blenders. Planetary blenders involve two movements of the impeller to be sure that all the powder in the tank is stirred. In the present work, we study the capabilities of a batch convective planetary blender to stir cohesive powders.

During mixing operations, power consumption is an important parameter to optimize. Furthermore recording power consumption is a way to understand mechanisms inside the blender's tank. This has 
been first studied during the early 1960s in concrete manufacturing [8]. For instance, during the mixing of powders and liquids, the torque measurement provides enough information to decide whether the operation should be stopped to get the wanted product [9]. Bagster and Bridgewater investigated the force needed to move dry particles with a blade at lab scale [10], using dimensional analysis [11]. Several studies provide dimensionless correlations for scale up to foresee power consumption in powder mixing at industrial scale with fewer experiments (Table 1). Most of them involve a power number and a Froude number, representing dimensionless power and agitation speed respectively.

In Table 1, most studies have been carried out using free flowing powders [12-16] while dry cohesive powders have only been investigated in two published works $[17,18]$. The first one determined coefficients in the correlations obtained with two free flowing powders and a cohesive powder. It was suggested, as a perspective, to link these coefficients with the rheological properties of the powders. The second one used only food cohesive powders and tried to link power consumption with cohesion through a dimensionless cohesion number in a continuous blender.

In this work and as a first approach, we study power consumption to highlight the different behaviors of cohesive and free-flowing powders in a planetary blender. Then, with the help of dimensional analysis, we link together the modified power number, the modified Froude number, the powder cohesion and the blender's filling ratio. This work aims to contribute to the understanding of the influence of cohesion in powder stirring. It is a first step towards the establishment of a model of powder flow in planetary blenders.

\section{Materials and methods}

\subsection{Powder characterization}

Five powders were studied: semolina (Le Renard), lactose (Granulac140), fine lactose (Granulac230), talc (Luz00) and sand (Société Nouvelle du Littoral). Semolina is the only free flowing powder, the other four being cohesive. The sand used here is not free flowing because it has been crushed. Two kinds of mixtures made of free flowing and cohesive powders are also studied to complete the panel of powder properties, the composition of which can be appreciated in Table 2 .

These powders were chosen for their different properties: particle size, shape and chemical composition. Semolina, lactose and fine lactose are organic powders; talc and sand are mineral powders. Each experiment was carried out with fresh powders, taken out of their sealed bags, especially for the organic ones, which may degrade quickly. These relatively complex powders were considered instead of classical model powders like glass beads, as this work aims to understand rheology with a process viewpoint to be applied directly in industries. Semolina and lactose are involved in agro food industry, lactose in pharmaceutical industry. Talc is used in a very wide range of domains: pharmaceutical, agro food, construction, cosmetic... and sand is mainly used in construction.

The shapes of semolina, lactose, fine lactose and sand are polygonal while talc is made of platelets (Fig. 1). SEM pictures also show that each powder is polydisperse in particle size. The particle's median diameter $\mathrm{d}_{50}$ was measured with a LASER diffraction particle sizer Mastersizer3000 (Malvern) under an air pressure of $3.5 \mathrm{bar}$, the particle density $\rho_{p}$ was measured using an Accumulator Pyc 1330 (Micromeritics) with the $10 \mathrm{~cm}^{3}$ cell. The bulk and tapped densities, $\rho_{b}$ and $\rho_{t}$, were measured with a volumenometer (Erweka) with $110 \mathrm{~g}$ of powder, the tapped density being measured after 1000 taps, which is enough to be sure that the powder cannot be more packed by the apparatus since the volume stabilizes around 300 taps. Each characterization was made at least in duplicate, the mean values being given in Table 2 and Fig. 2. Mixtures were prepared by adding the ingredients to a half liter transparent container, and further blend it with a spatula for at least $1 \mathrm{~min}$ until the mixture appears homogenous. The mixture quality was good enough to have no influence on the density measurement, which is verified by the small standard deviation on the repeated tests. Bulk and tapped densities allow calculation of the Carr Index (Eq. (1)), which is a characteristics of powder flowability [19].

$$
C I=100 \cdot \frac{\rho_{t}-\rho_{b}}{\rho_{t}}
$$

Fig. 3 and Table 2 represent Carr Index values for single powders and mixtures. As reported by Leturia et al. [20], the typical scale of flowability used to classify powder flow behavior shows that powders of Carr Index between 5 and 15\% are easy flowing, between 15 and $22 \%$ the behavior is intermediate, while when higher than $22 \%$, it reveals a bad flowing powder. To ease the interpretations in this study, we will consider that for a Carr Index below $15 \%$ the powder is free flowing and above $15 \%$ the powder is cohesive. Considering the data in Table 2, semolina is free flowing and lactose, fine lactose, talc and sand can be considered as cohesive. For mixture 1 , if the lactose content is smaller than $50 \%$ the powder is free flowing, and when it is bigger the powder is cohesive (Fig. 3). For mixture 2, powders are cohesive when the fine lactose content is bigger than $30 \%$.

The FT4 $₫$ rheometer by Freeman Technology is used as shear device, with its rotational shear cell (Fig. 4). This apparatus imposes a normal stress to the powder bed while the shear stress is recorded. Cohesion is measured according to the standard protocol for the FT4 shear testing. The powder is poured into the cylindrical vessel, and its volume is fixed using the rotating part on the top of the vessel that can be seen in Fig. 4 . The powder is conditioned by a blade getting downward and upward through the testing cell. Yield locus are built as follows: (1) powder is pre-sheared at a normal pre-consolidation load (2) the sample is sheared under smaller consolidation values, increasing up to the preconsolidation one, in order to measure the shear stress peaks characteristics of the powder bed rupture.

For a given pre-consolidation, the major principal stress $\sigma_{1}$ and the unconfined yield strength $\sigma_{c}$ [21] are determined graphically from the Yield locus (Fig. 5(a)) and lead to build flow functions (Fig. 5(b)) that are needed for silo design, for example. Flow functions allow the description of the flowing behavior of powders whatever their consolidation state. They give the possibility to gather results obtained under different procedures [22]. The flow function's representative numerical value is the slope but as far as flow functions are often not straight-lines

Table 1

Dimensionless correlations on powder mixers reported in the existing literature.

\begin{tabular}{lll}
\hline Blender type & Dimensionless correlation & Powders studied \\
\hline Vertical stirrer & $N_{p}=a \cdot N_{M}^{-1}+b$ & Reference \\
Nautamix & $N_{p}=k \cdot\left(N_{v} / N_{a}\right)^{m} \cdot\left({ }^{L} / D_{v}\right)^{n}$ & Sand, alumina, hematite, glass beads, millet, polystyrene \\
Horizontal drum & $N_{p}=a \cdot F_{r}^{-1}+b$ & \\
High shear & $N_{p}=a \cdot F_{r}^{1 / 2}+b$ & Sand, alumina, glass, PVC, limestone \\
Triaxe ${ }^{\circledR}$ & $N_{p M}=a \cdot F_{r M}^{b}$ & Glass spheres, sand \\
Helical double ribbon & $N_{p}=K_{p e} \cdot N_{c e}^{-1.03}$ & Couscous, semolina, lactose \\
\hline
\end{tabular}


Table 2

Physical characteristics of the powders studied: mean particle size as obtained by LASER diffraction, bulk densities measured by a volumenometer Erweka ${ }^{\circledR}$, true density measured by a He pycnometer, cohesion measured by a FT4 rheometer. Available properties are mentioned for the mixtures as well as their compositions.

\begin{tabular}{|c|c|c|c|c|c|c|}
\hline Powder & $d_{50}(\mu \mathrm{m})$ & $\rho_{p}\left(\mathrm{~kg} \cdot \mathrm{m}^{-3}\right)$ & $\rho_{b}\left(\mathrm{~kg} \cdot \mathrm{m}^{-3}\right)$ & $\rho_{t}\left(\mathrm{~kg} \cdot \mathrm{m}^{-3}\right)$ & Carr Index (\%) & Cohesion $(\mathrm{kPa})$ \\
\hline \multicolumn{7}{|c|}{ Properties of pure powders } \\
\hline Semolina & 312 & 1463 & 679 & 720 & 5.8 & $0.244 \pm 0.098$ \\
\hline Lactose & 61 & 1533 & 661 & 795 & 16.9 & $0.745 \pm 0.116$ \\
\hline Fine lactose & 26 & 1539 & 495 & 638 & 22.5 & $1.115 \pm 0.133$ \\
\hline Talc & 16 & 2772 & 501 & 848 & 40.9 & $0.535 \pm 0.070$ \\
\hline Sand & 33 & 2643 & 887 & 1222 & 27.4 & $0.593 \pm 0.039$ \\
\hline
\end{tabular}

Properties of powder mixtures by wt\%:

M1 (semolina: lactose) and M2 (semolina: fine lactose)

1 $1(10: 90)-10$

M1 (20:80) N.A. N.A.

M1 (30:70) N.A. N.A.

M1 (40:60) N.A. N.A.

M1 (50:50) N.A. N.A.

M1 (60:40)

M1 (70:30)

M1 (80:20)

M1 (90:10)

M2 (10:90)

M2 (20:80)

M2 (30:70)

M2 (40:60)

M2 (50:50)

M2 (60:40)

M2 (70:30)

M2 (80:20)

M2 (90:10)

N.A.

N.A.

$\begin{array}{ll}\text { N.A. } & \text { N.A. } \\ \text { N.A. } & \text { N.A. }\end{array}$

N.A. N.A.

N.A. N.A

N.A. N.A

N.A. N.A.

N.A. N.A.

N.A. N.A

N.A. N.A.

N.A. N.A.

N.A. N.A

N.A.

N.A.

\begin{tabular}{llll}
724 & 792 & 8.6 & 0.17 \\
761 & 840 & 9.4 & 0.17 \\
793 & 901 & 12.0 & 0.24 \\
817 & 935 & 12.6 & 0.36 \\
781 & 946 & 17.4 & 0.5 \\
761 & 929 & 18.1 & 0.65 \\
744 & 900 & 17.3 & 0.7 \\
695 & 864 & 19.6 & 0.78 \\
685 & 824 & 16.9 & 0.75 \\
704 & 766 & 8.1 & 0.16 \\
706 & 816 & 13.5 & 0.17 \\
698 & 854 & 18.2 & 0.34 \\
681 & 859 & 20.7 & 0.57 \\
655 & 833 & 21.4 & 0.94 \\
599 & 785 & 23.6 & 1.23 \\
582 & 741 & 21.5 & 1.29 \\
517 & 697 & 25.9 & 1.16 \\
482 & 660 & 26.9 & 1.20 \\
\hline
\end{tabular}

passing by the origin like in Fig. 5(b) (see [23]), the ratio ffc of $\sigma_{1}$ and $\sigma_{c}$ for given pre-consolidation states is widely used. That limits the interest of the method.

As far as cohesion quantifies the interaction forces between particles, it should be considered as a key property that influences the way particles are flowing and insofar the flow pattern during agitation in a vessel. Cohesions derived from the Yield locus correspond to 2, 4, 8 and $16 \mathrm{kPa}$. Each measurement was repeated twice for three powders. As far as levels of consolidation expected for powders during a mixing operation are small, we chose to consider cohesion measurements obtained at $4 \mathrm{kPa}$ (Table 2). It must be noted that experiments at $2 \mathrm{kPa}$ are not reproducible for finer powders like talc and fine lactose.

\subsection{Experimental set up and procedure}

The Triaxe $®$ is a four bladed mixer that operates thanks to a dual motion of rotation and gyration (Fig. 6). It is designed so that the impeller system covers the whole volume of the blender. The four rectangular blades, made of stainless steel, are inclined at about $45^{\circ}$, the angle between each blade being $90^{\circ}$. The angle between the horizontal and the gyration axis is about $15^{\circ}$. The stainless steel spherical tank has a volume of 481 and the distance between the vessel and the blades is about $1 \mathrm{~mm}$. The powder is loaded by the top and drained from the bottom. More detailed information about this kind of mixer can be found in Demeyre's PhD thesis [24].

Two torque-meters record the rotational and the gyrational torque. If $\omega$ is the angular speed ( $\mathrm{rad} \cdot \mathrm{s}^{-1}$ ) and $T$ is the torque $(\mathrm{N} \cdot \mathrm{m})$, the power $P(\mathrm{~W})$ needed to stir the powder load can be calculated as follows (Eq. (2)):

$P=\omega_{g m} \cdot\left(T_{g f}-T_{g 0}\right)+\omega_{r m} \cdot\left(T_{r f}-T_{r 0}\right)$

with subscripts "g" for gyration, " $r$ " for rotation, "f" for filled tank, "0" for empty tank and " $m$ " for motor.

Angular speeds are expressed as the speed of motors, using reduction ratios of the apparatus; the angular speeds of axis $\omega_{g a}$ and $\omega_{r a}$ can be calculated thanks to Eqs. (3) and (4). Speeds of the axis reach about 20 revolutions per minute (rpm) and $100 \mathrm{rpm}$ for gyration and rotation respectively.

$\omega_{g a}=\frac{\omega_{g m}}{144.79}$

$\omega_{r a}=\frac{\omega_{r m}}{34}+0.59 \cdot \omega_{g a}$

Each pilot scale experiment is performed with $30 \mathrm{~kg}$ of powder, following the protocol: torque stabilization during $2 \mathrm{~h}$ with $\omega_{g m}$ and $\omega_{r m}$ about $2000 \mathrm{rpm}$, measurement of mean torques with empty mixer $\left(T_{g 0}\right.$ and $\left.T_{r 0}\right)$, loading of the powder, stirring during $10 \mathrm{~min}$ with $\omega_{g m}$ and $\omega_{r m}$ about $2000 \mathrm{rpm}$ to mix the powder enough in order to stabilize the torque, recording of mean torques with filled mixer $\left(T_{g f}\right.$ and $\left.T_{r f}\right)$, and finally tank emptying and cleaning.

Torque measurements correspond to combinations of speeds $\omega_{g m}$ and $\omega_{r m}$ ranging from 0 to $3000 \mathrm{rpm}(0,75,150,300,600,900,1500$, 2100 and $3000 \mathrm{rpm}$ ). This means that for each powder studied, 81 pairs $\left(\omega_{g m}, \omega_{r m}\right)$ have been considered. Fig. 7 describes the sequence of gyrational speeds and rotational speeds used during experiments. First, the gyration is fixed and the rotation increases. When the rotation reaches its maximum value, the gyration speed is increased to the following value and the rotation starts again at its smaller value. It is important to notice that because of the dependence of the rotational angular speed of blades $\omega_{r a}$ on the gyrational angular speed of blades $\omega_{g a}$ (Eq. (4)). Agitation angular speeds are expressed as angular speeds given by the motor $\omega_{g m}$ and $\omega_{r m}$ for a better understanding.

The filling ratio $f$ may be calculated using the bulk density $\rho_{b}$, the tank volume $V_{\text {tank }}$ and the mass of powder poured $m_{p}$ (Eq. (5)). The filling weight of $30 \mathrm{~kg}$ of each powder corresponds to $f$ values in the range $0.70-1.26$. For $f$-values $>1$, the powder was forcibly compacted into the blender.

$f=\frac{m_{p}}{\rho_{b} \cdot V_{\text {tank }}}$

Experiments with varying filling weights of a same powder were conducted in order to complete these runs. For this, three additional 

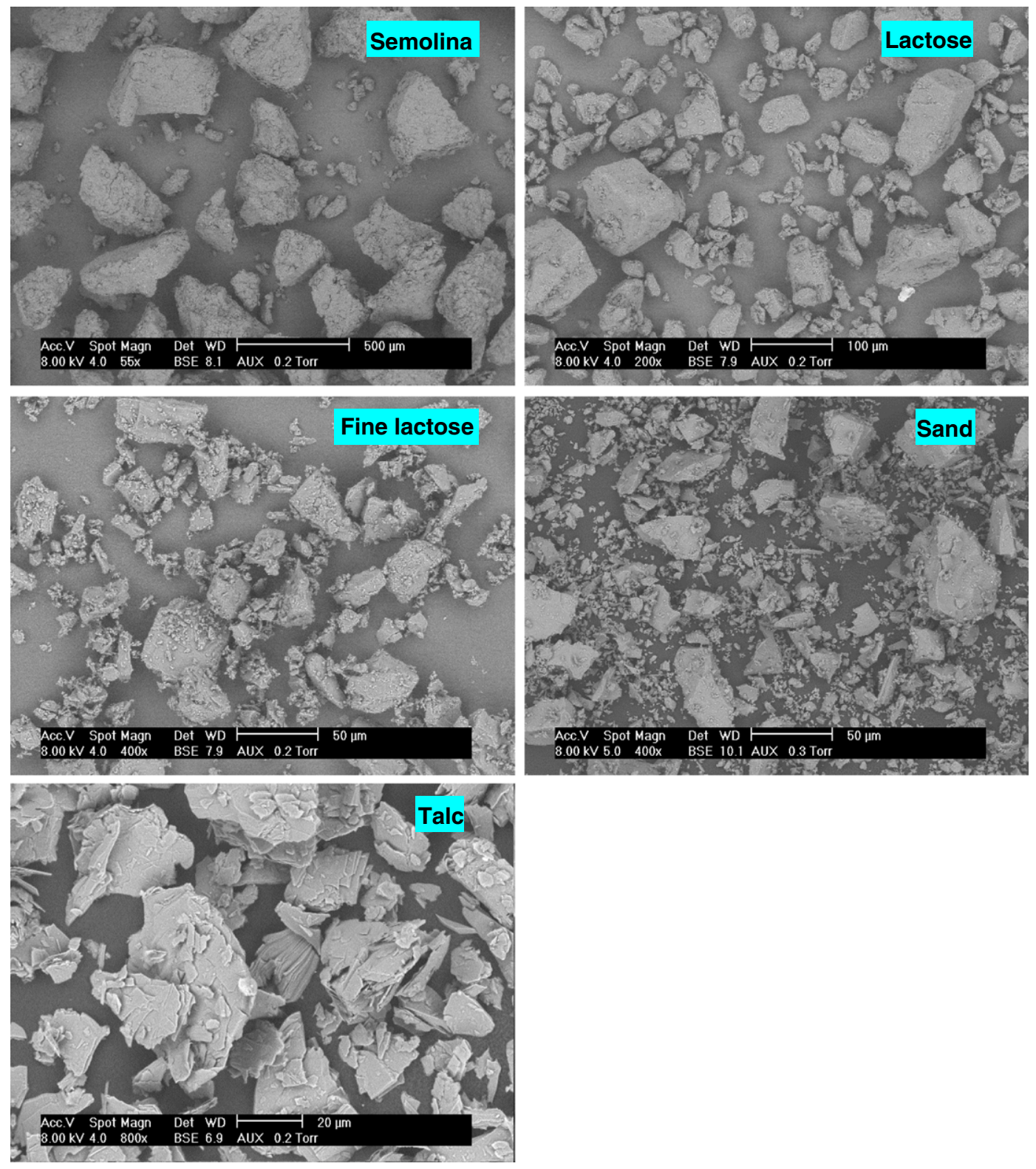

Fig. 1. SEM pictures of semolina (top left), lactose (top right), fine lactose (mid left), sand (mid right) and talc (bottom left).

filling ratios were investigated for semolina and lactose: $0.42,0.63$ and 0.83 (Table 3).

A characteristic tip speed $u_{c h}$ has been set up by Delaplace et al. [25] to combine gyrational and rotational speeds into a single value. It corresponds to the maximum linear tip blade velocity divided by $\pi$. Eqs. (6) and (7) can be used to calculate $u_{c h}$ with: $d_{s}=0.112 \mathrm{~m}$ the diameter of the spherical reducer of the blender and $D=0.448 \mathrm{~m}$ the distance between two opposite blade tips. In both equations, angular
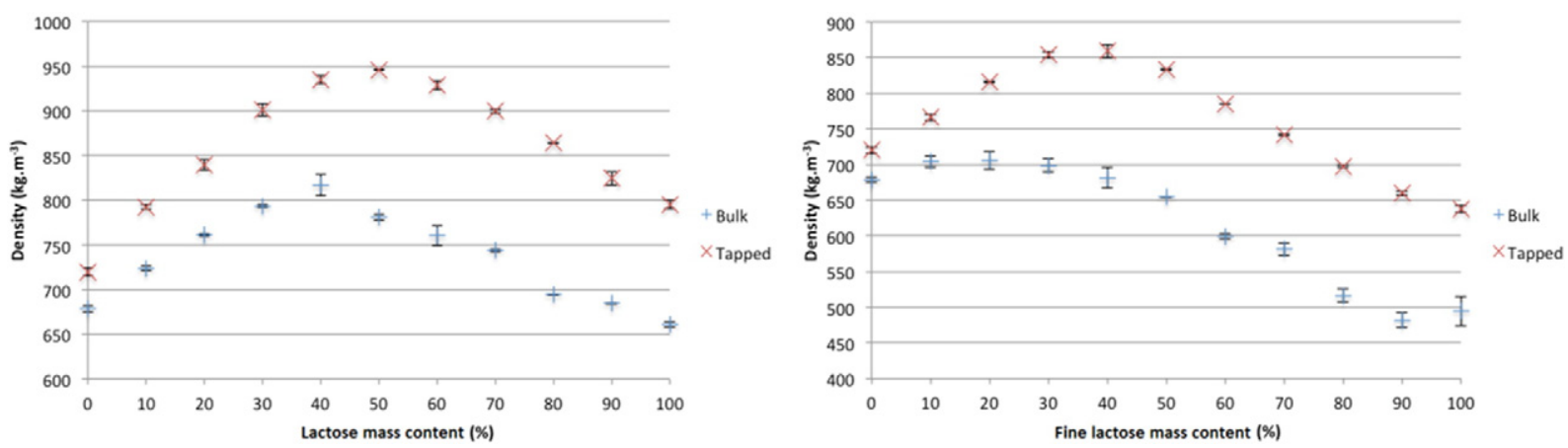

Fig. 2. Apparent densities measured for mixture 1 (left) and mixture 2 (right) as a function of composition. 


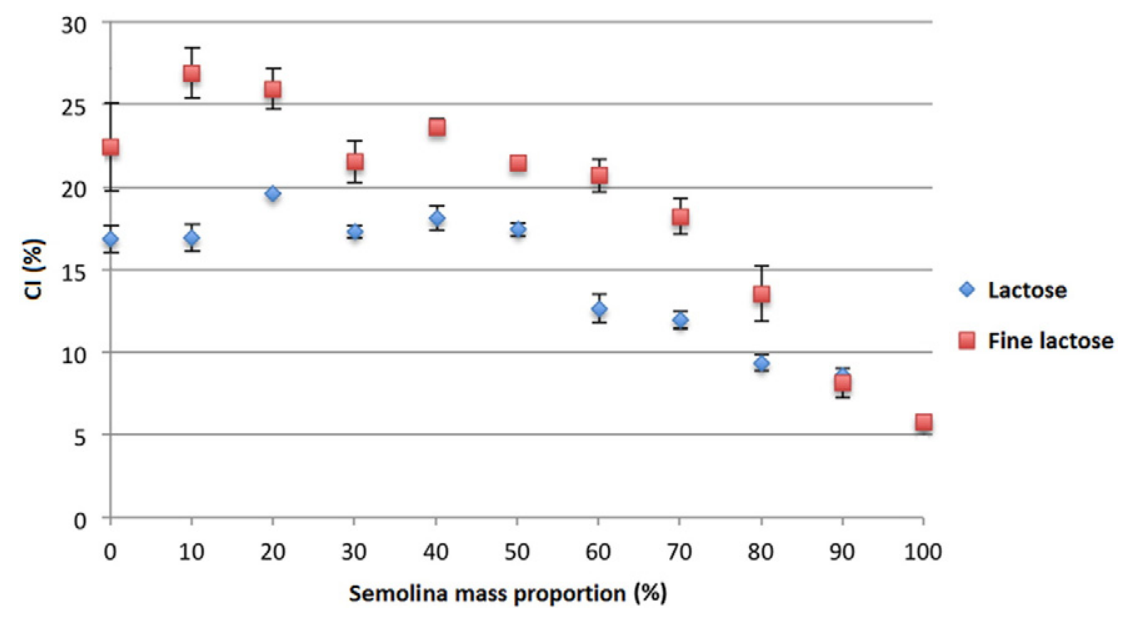

Fig. 3. Carr Indexes calculated for both mixtures.

speeds are written as $\Omega_{g a}$ and $\Omega_{r a}$ for gyration and rotation. The units should therefore be in revolutions per second.

$\frac{\Omega_{r a} \cdot d_{s}}{\Omega_{g a} \cdot D}<1 \rightarrow u_{c h}=\sqrt{\left(\Omega_{g a}^{2}+\Omega_{r a}^{2}\right) \cdot\left(d_{s}^{2}+D^{2}\right)}$

$\frac{\Omega_{\mathrm{ra}} \cdot d_{s}}{\Omega_{g a} \cdot D}>1 \rightarrow u_{c h}=\Omega_{r a} \cdot D+\Omega_{g a} \cdot d_{s}$

The impact of both rotational and gyrational speeds on $u_{c h}$ can be appreciated on the 3-D graph in Fig. 8. It can be stated that rotational speed has a greater influence on the characteristic speed than the gyrational speed. The surface represented is almost planar except for the small values of the rotational speed and the highest ones of the gyrational speed, which are not in the expected range of operation of a planetary mixer. In addition, if a projection of these values on the $\left(u_{c h}, \Omega_{r a}\right)$ plane is made, the whole values are collapsing in a single line, mainly because $d_{s}$ is much smaller than $D$.

Through the use of $u_{c h}$, a dimensionless correlation (Eq. (10)) [16] links a modified Froude number $F_{r M}$ (Eq. (8)) and a modified power number $N_{p M}$ (Eq. (9)) [25], where $g=9.81 \mathrm{~m} \cdot \mathrm{s}^{-2}$.

$F_{r M}=\frac{u_{c h}^{2}}{g \cdot d_{s}}$
$N_{p M}=\frac{P}{\rho_{b} \cdot u_{c h}^{3} \cdot d_{s}^{2}}$

$N_{p M}=a \cdot F_{r M}^{b}$

To get a better understanding of the meanings of this correlation, the power can be expressed directly as a function of $u_{c h}$ and the two coefficients $a$ and $b$ (Eq. (11)) from Eqs. (8), (9) and (10).

$P=\left(\rho_{b} d_{s}^{2-b} g^{-b}\right) a u_{c h}^{3+2 b}$

It has been previously reported that for a free flowing powder $b=-1$ [17]. In Eq. (11), it means that the power is a linear function of $u_{c h}$. If the powder is cohesive, $b$ will be closer to $-3 / 2$, meaning that the power is not dependent on $u_{c h}$ [17].

\section{Results and discussion}

\subsection{Power consumption during Triaxe experiments}

This part presents power consumption in the pilot blender for the five "pure" powders studied. The power measured depends on the flow inside the blender since it represents the forces exerted by the blades on the powder, which are more or less transmitted throughout the powder bed, thanks to avalanches, frictions or collisions between particles.
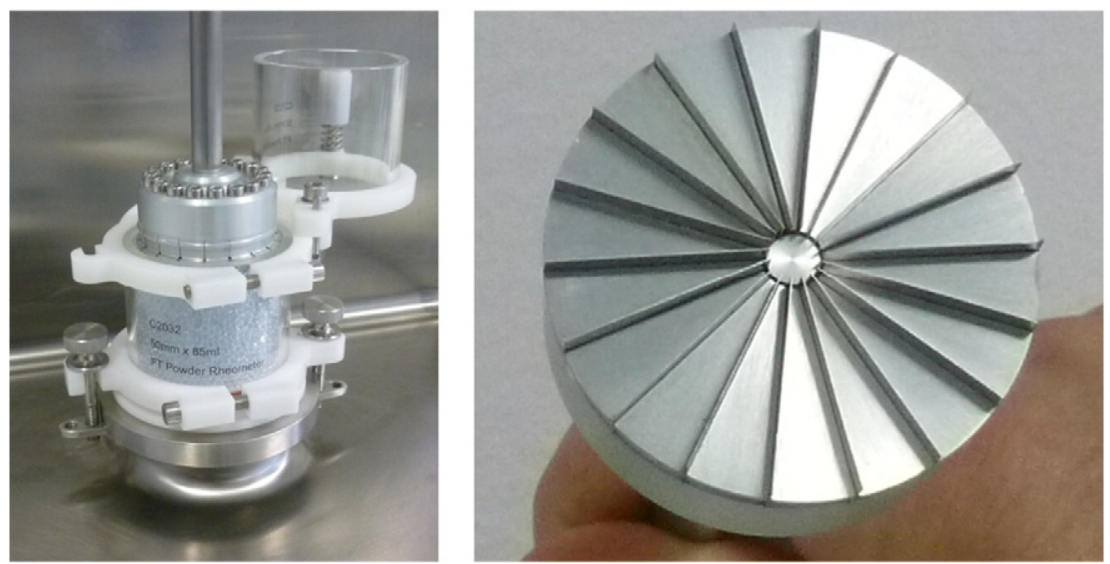

Fig. 4. FT4 Freeman rheometer (left) and shear cell (right). 
a)

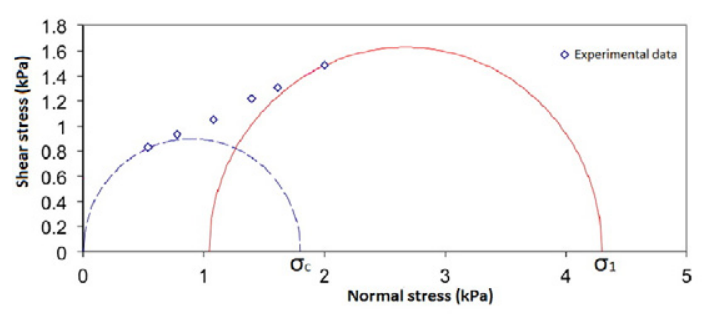

b)

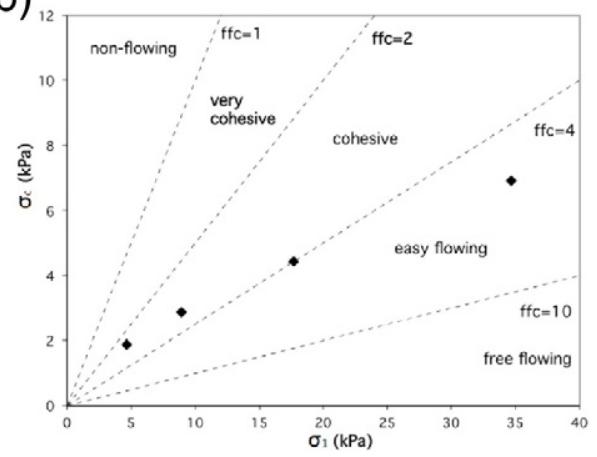

Fig. 5. Examples of lactose Yield locus (a) and flow function (b).

In Fig. 9, the power for semolina is on average higher than the power for any of the four other powders. In addition, it is almost a linear function of the characteristic tip speed. Concerning cohesive powders, the power is obviously less sensitive to a blade speed increase, especially for lactose, talc and sand.

On Fig. 10, that shows power consumptions for cohesive powders in more detail, the global tendency is characterized by a significant increase of the power at small $u_{c h}$ (up to $0.1 \mathrm{~m} \cdot \mathrm{s}^{-1}$ ), followed by a smaller increase for higher speeds. The values that do not seem to follow this trend and are characterized by a much smaller $P$, have been obtained with very small values of the gyrational speed. They can be considered to be out of the normal range of use of a planetary mixer, for which blades have to describe the whole mixer's volume in an acceptable time. This is emphasized in Fig. 11, for which the equipment has been set to operate without gyration (discontinuous line). In this case, the impeller stirs a smaller powder mass, which is not what may be expected. This is all the more significant in the case of cohesive powders for which shear mixing at the blade-powder interface do not exist in practice. That said, it must be beared in mind that the use of $u_{c h}$ in the prediction of the power is limited to the range of speed combination excluding small gyrational speed values.

When gyrational speed increases for a fixed rotational speed (continous lines), the power increases, because the four blades move into the stationary powder bed that was out of reach for them. In fact, this powder rheology analysis puts forward the interest of a planetary blender: the rotation creates a mixing zone for the product and the gyration moves this zone in other parts of the vessel. This impact of gyration is more visible on lactose, less for fine lactose and talc, and almost not observable for sand (Fig. 10). This smaller implication of gyration for sand is probably due to its higher bulk density (Table 3 ), so blades are partially immerged as compared with other powders. This difference in rheological behavior between free flowing and cohesive powders has already been studied for semolina, couscous and lactose [17]. Now we can see that it is also the case for milled sand, of higher density than lactose, talc particles of platelet shape and for fine lactose, made of finer particles. In the case of sand powder it can be noted that no repeatability tests have been done, because this powder is too abrasive and dense, $30 \mathrm{~kg}$ of this material being able to damage the mixer for higher agitation speeds.

In order to get rid of the differences in bulk density between the powders and in the objective to generalize our work (for different scales of tank for instance), these results are featured by the dimensionless correlations highlighted before: $N_{p M}=a \cdot F_{r M}^{b}$ [16]. Coefficients $a$ and $b$ are identified by regression as shown in Fig. 12, for semolina and lactose, chosen here as examples to highlight that the power correlation is more reliable for free flowing powders. Coefficients $a$ and $b$ are represented in Fig. 13 as a function of semolina content.

\subsection{Correlation between dimensionless coefficients and cohesion}

Cohesion is the property chosen to distinguish powders. This part puts forward the cohesion dependence of the coefficients $a$ and $b$ of the dimensionless correlation between the modified power number and the modified Froude number (Eq. (10)). These coefficients have been calculated using torque measurements for the five single powders and of the 16 mixtures, the blender still being filled of $30 \mathrm{~kg}$ for each batch. Linking $a$ and $b$ with a powder property is interesting to limit the powder quantity, the time and efforts spent to perform experiments in blenders, that are usually costly in industry.

Table 4 lists coefficients $a$ and $b$ calculated for each powder and the regression coefficients $\mathrm{R}^{2}$ corresponding to each correlation. The regression coefficient is smaller for cohesive powders and closer to 1 for
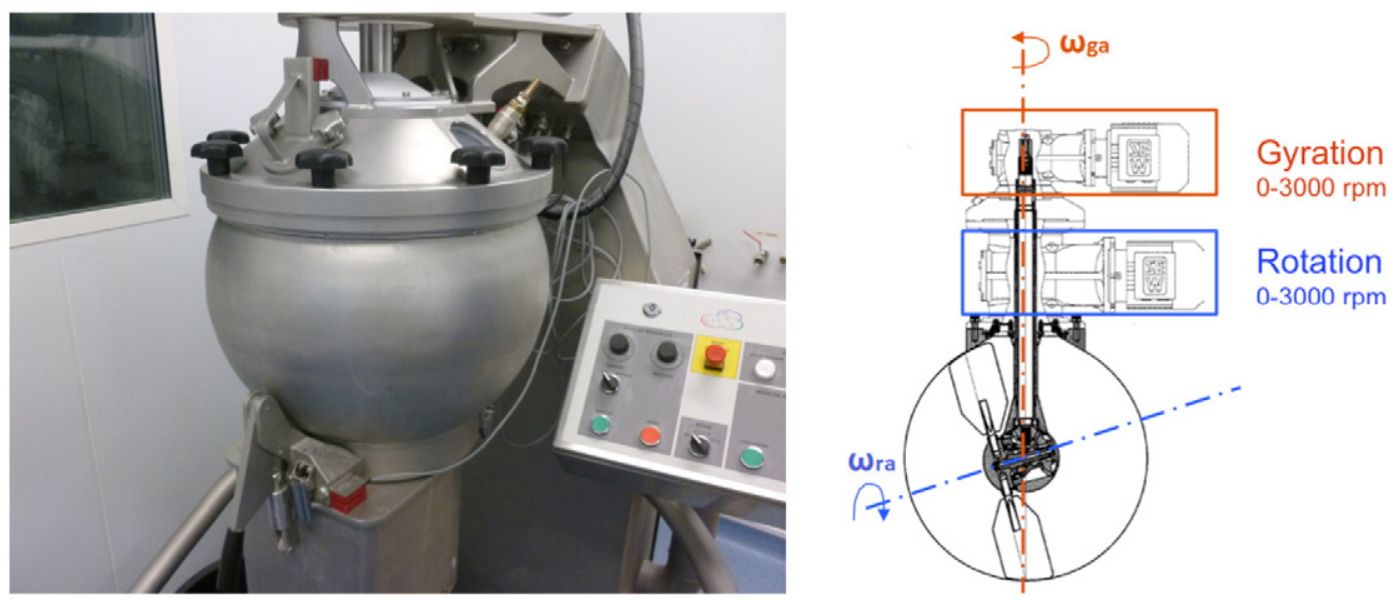

Fig. 6. Triaxe blender (left) and schematic diagram (right). 


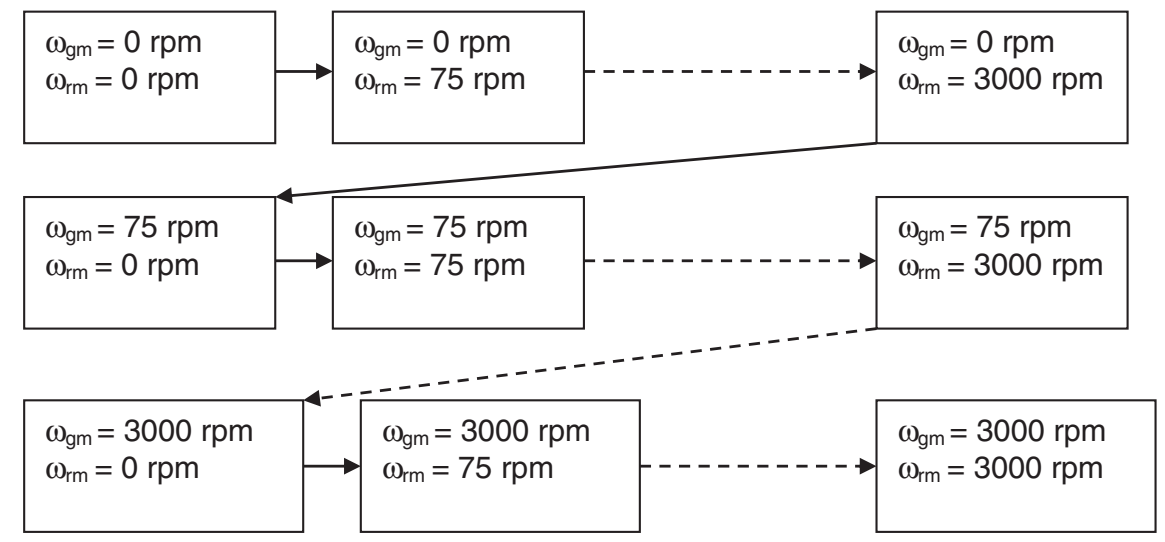

Fig. 7. Diagram showing the procedure followed for rotation and gyration changes during the experiments.

Table 3

Lactose and semolina weights, volumes and filling ratios studied.

\begin{tabular}{lllllllll}
\hline \multicolumn{3}{c}{ Semolina } & \multicolumn{7}{c}{ Lactose } \\
\hline Mass (kg) & 13.7 & 20.5 & 27.1 & 30.0 & 13.3 & 20.0 & 26.3 & 30 \\
Volume (L) & 20 & 30 & 40 & 44 & 20 & 30 & 40 & 45 \\
$f$ & 0.42 & 0.63 & 0.83 & 0.92 & 0.42 & 0.63 & 0.83 & 0.94 \\
\hline
\end{tabular}

semolina. This is due to the dispersion of power values owing to gyration impact, as explained before. Coefficients for mixtures 1 and 2 are shown in Fig. 13. In this, $a$ values seem to decrease linearly with a decreasing semolina content for both kind of mixtures and when the cohesive powder content is bigger than $60 \%$, the cohesion remains the same. $b$ coefficients show a relatively linear increase with the free-flowing powder content. Single fine lactose coefficients do not follow the trends observed.

The cohesion of single powders is represented on Table 2. Semolina has the smallest cohesion as expected and fine lactose is the most cohesive powder. Fig. 14 represents the evolution of the cohesions of mixtures 1 and 2 with semolina content, for both lactose and fine lactose. As expected, the cohesion increases as the content in cohesive powder increases. Below $30 \%$, the cohesion is close to the semolina's one, being that of lactose or fine lactose after $70 \%$. It looks linear between 30 and $70 \%$.

In a second approach, $a$ and $b$ coefficients can be expressed as a function of cohesion for all mixtures and for single powders. They both seem to decrease with cohesion for the large majority of powders (Fig. 15). The fine lactose has an unexpected behavior, which is probably due do its tendency to agglomerate as it has been denoted during the experimental handling of this powder among all experiments. From an industrial viewpoint, a global correlation for $a$ and $b$ can be admitted to get a first estimation of the power consumption, depending on the cohesion $c$ of the powder (Eq. (12)).

$N_{p M}=\frac{5.4}{c} \cdot F_{r M}^{b}$

with $b=0.47 c^{2}-0.94 c-0.87$

The squared coefficients of correlations for $a(0.73)$ and $b(0.85)$ are relatively small. If we except the singular points corresponding to the

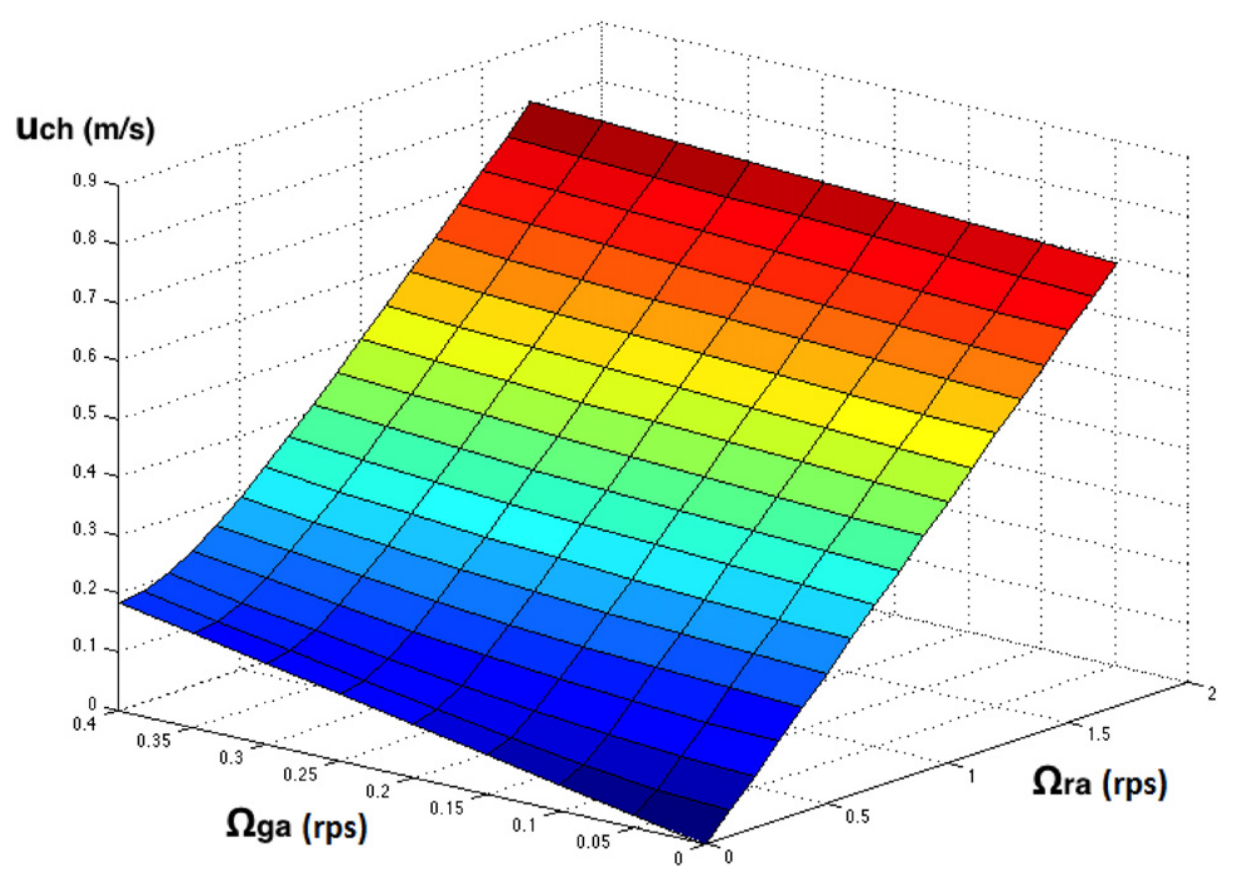

Fig. 8. Influence of both rotational and gyrational speeds on $u_{c h}$. 


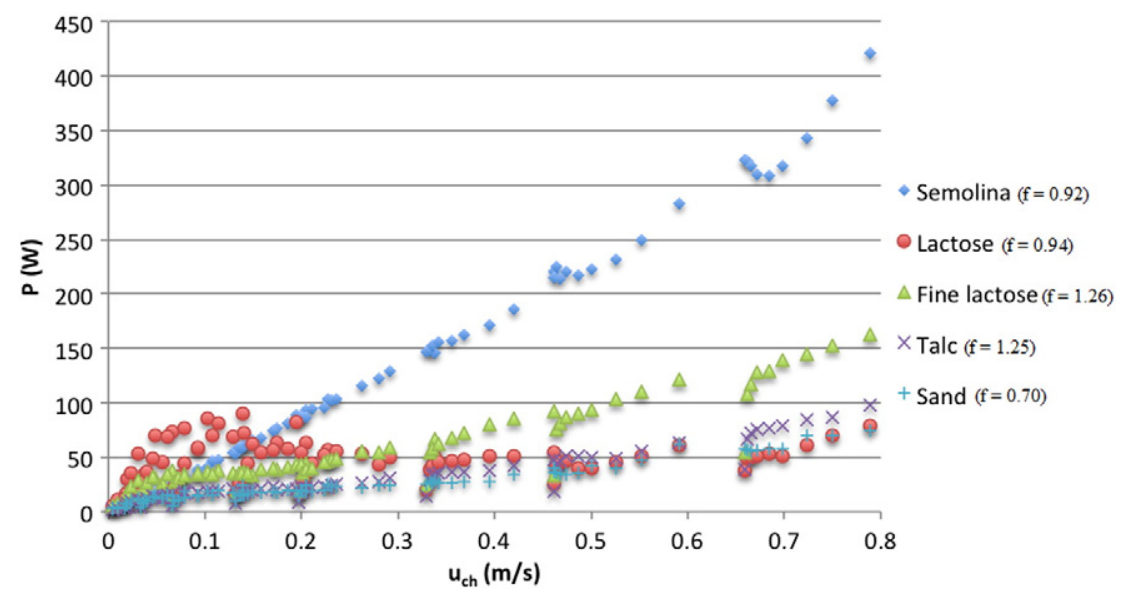

Fig. 9. Influence of the nature of particulate system on the $P$ vs $u_{c h}$ charts for $30 \mathrm{~kg}$ of powder filling in the Triaxe® blender.

single fine lactose, a closer look to the graphs demonstrates two extreme cases depending on the cohesion:

if $c<0.3 \mathrm{kPa} \rightarrow N_{p M}=a \cdot F_{r M}^{-1}$

if $c>0.6 \mathrm{kPa} \rightarrow N_{p M}=6 \cdot F_{r M}^{b}$

The Carr Index (Eq. (1)) can be used to associate each group of powders with flowability: if it is smaller than 15 , the powder is free flowing while if it is higher, the flowability is affected. On Fig. 16, powders of cohesion smaller than $0.3 \mathrm{kPa}$ can be considered as free flowing and powders of cohesion bigger than $0.6 \mathrm{kPa}$ are classified as cohesive. This kind of representation has already been adopted to give an estimation of the flowability of powders using the flow function and the compressibility, both measured with a FT4 rheometer [20]. In both Eqs. (13) and (14), a and $b$ coefficients should be recalculated by forcing the regression with the constant $a$ or $b$ value. This will be done in the next part, where they will be expressed as functions of the filling ratio.
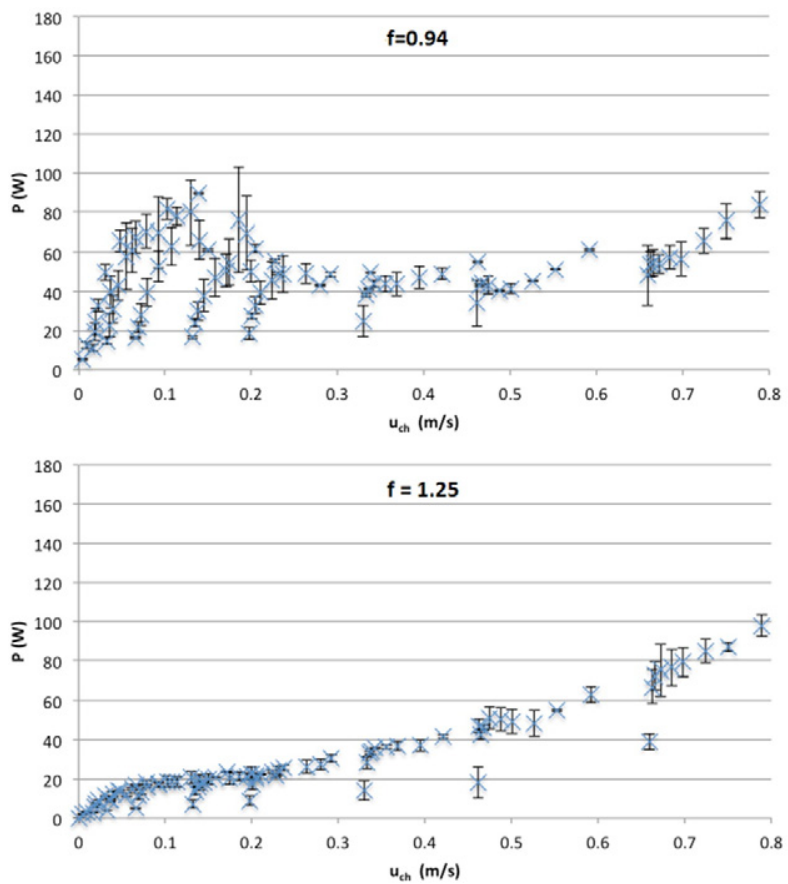

\subsection{Influence of the filling ratio}

In this first approach, experiments were carried out with a fixed mass of each powder ( $30 \mathrm{~kg}$ ), but as their bulk densities are ranging between 495 and $887 \mathrm{~kg} \cdot \mathrm{m}^{-3}$, filling ratios are different for different powders. Filling ratio is linked to the volume occupied by the powder and insofar to the immersion of the blades and to the local sate of consolidation of the bulk (maybe the coexistence of local dilated and consolidated zones).

Powders of two different flow properties have been chosen to investigate the influence of $f$ on the rheology: one is free flowing, semolina, and the other one is cohesive, lactose. Experiments were done at four filling ratios $(0.42,0.63,0.83,0.92$ or 0.94$)$ for each powder, see Table 3. Coefficients $a$ and $b$ are identified on the basis of correlations (13) and (14). Fig. 17 represents the linear dependence of $a$, plotted against $f$ for semolina and the linear dependence of $b$ on $f$ for lactose. Thus, correlations between the modified power number and the modified Froude number can be completed. For semolina, Eq. (13), which represents Eq. (10) when the $b$ coefficient is forced to -1 , should be used. The linear
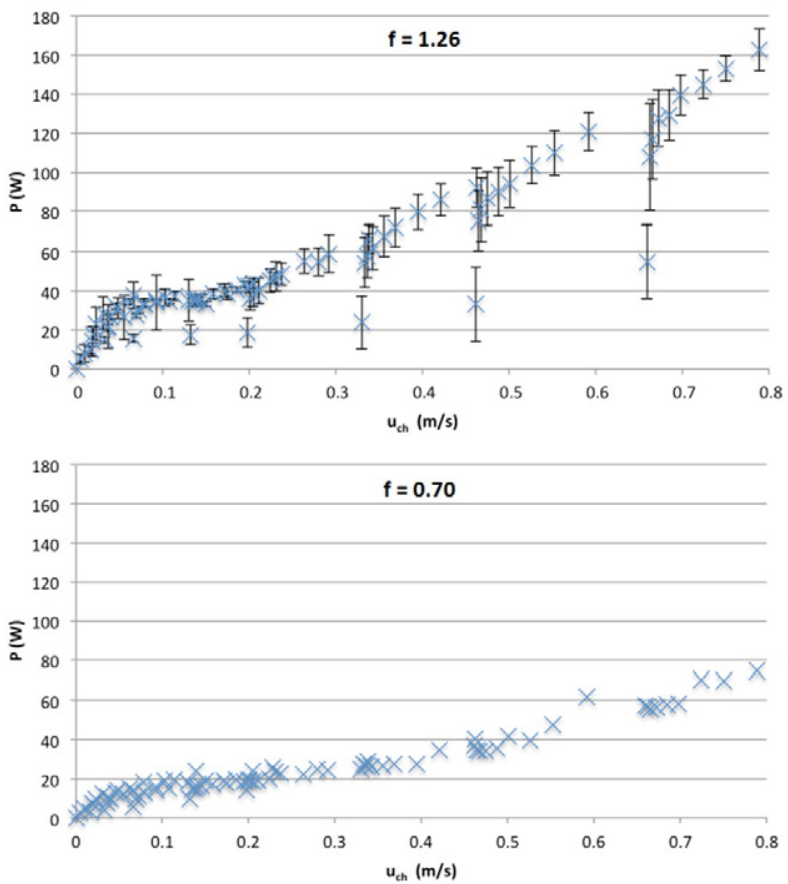

Fig. 10. Power consumptions recorded for lactose (top left), fine lactose (top right), talc (bottom left) and sand (bottom right), as a function of $u_{c h}$. 


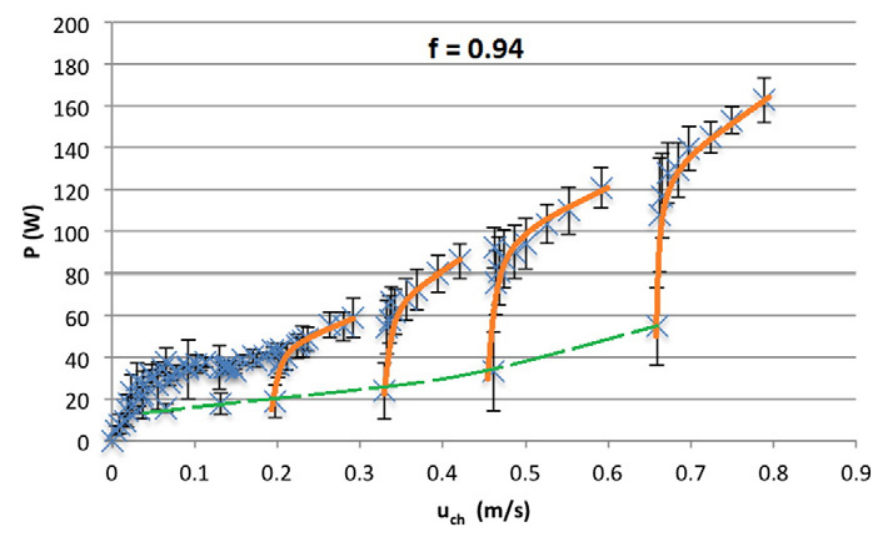

Fig. 11. Fine lactose power consumption with a set motor rotation (continuous lines) and no gyration (discontinuous line), as a function of $u_{c h}$.

regression of $a$ vs $f$ is relatively good $\left(\mathrm{R}^{2}=0.989\right)$ and we can express $a$ as follows (Eq. (15)):

$$
a=62 f-14
$$

Concerning lactose, Eq. (14) is better suited because its cohesion is higher than $0.6 \mathrm{kPa}$. The $b$ coefficient decreases linearly with $f$ (Eq. (16)) and the correlation is weaker than Eq. (15) for semolina $\left(\mathrm{R}^{2}=\right.$ 0.987).

$$
b=-0.52 f-0.92
$$

Experiments have also been performed with unclassified powders like fine lactose, as well as talc and sand of cohesions between 0.3 and
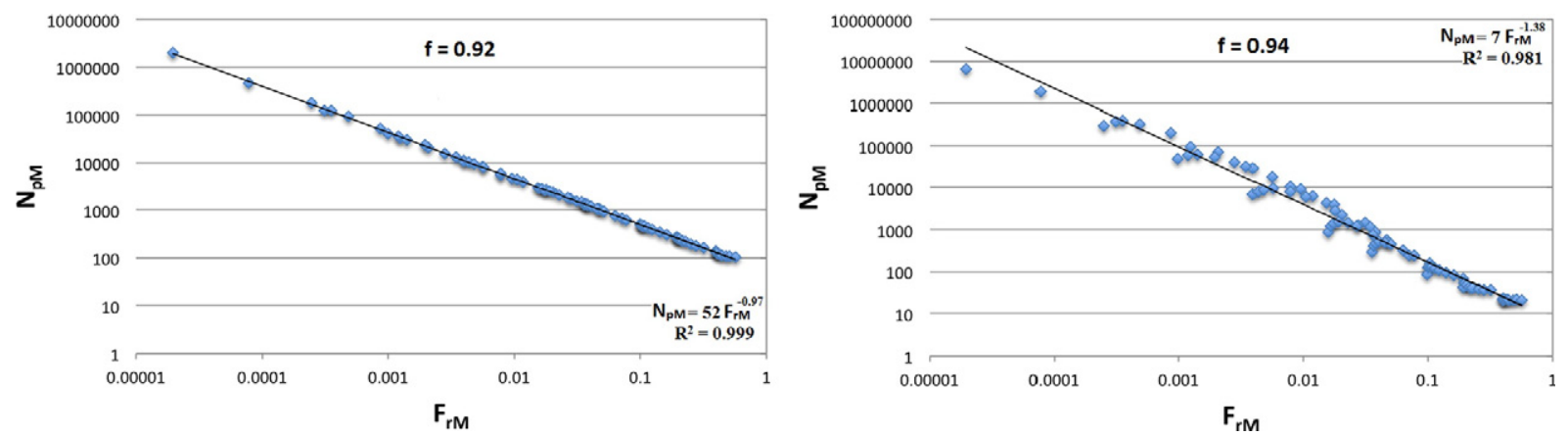

Fig. 12. Evidence of a power relationship between modified power number and modified Froude number for semolina (left) and lactose (right).
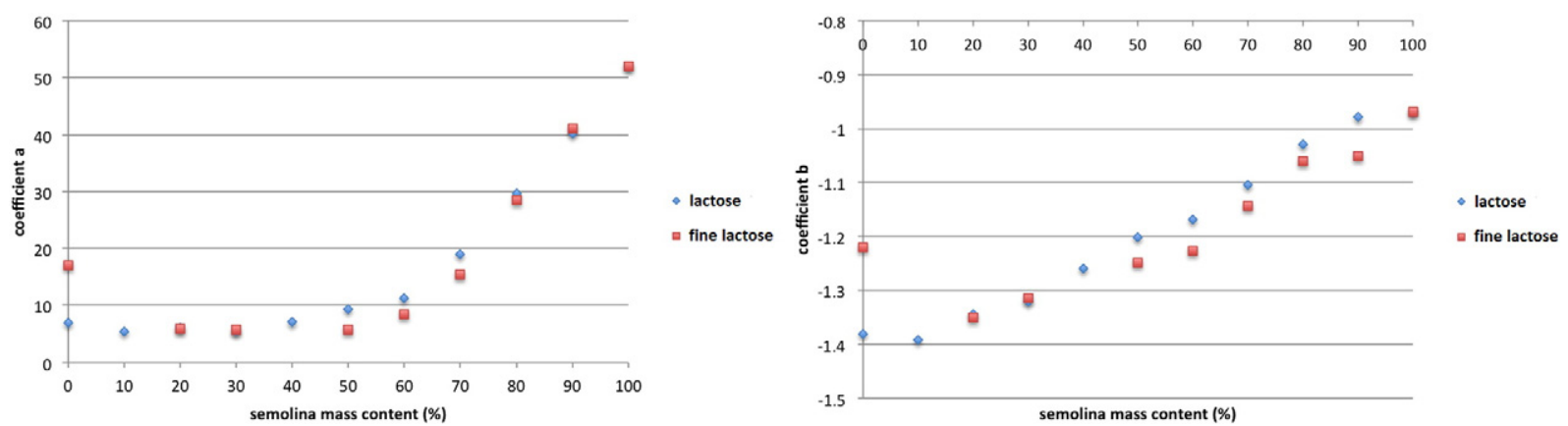

Fig. 13. Evolution of coefficients $a$ (left) and $b$ (right) as a function of semolina content in the mixtures studied. 


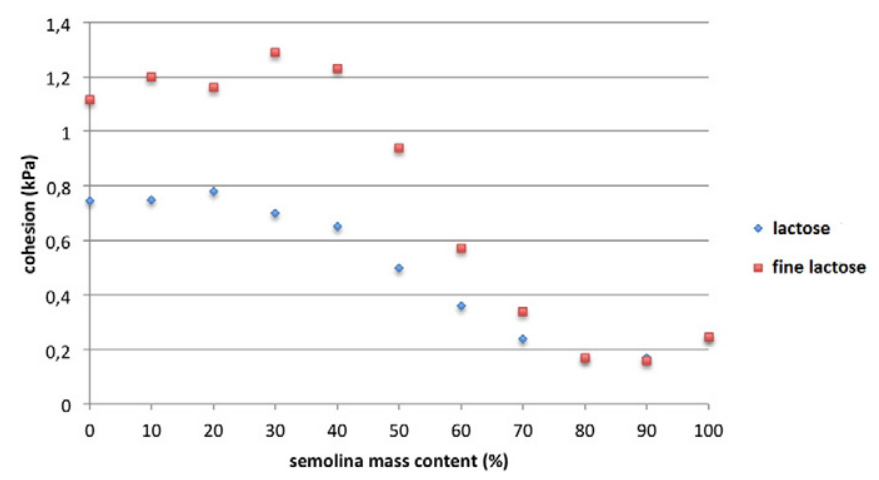

Fig. 14. Cohesion measured for mixture 1 (semolina-lactose) and mixture 2 (semolinafine lactose).

$0.6 \mathrm{kPa}$. For all of them, the dependency of $a$ and $b$ on the filling ratio is similar to that of lactose: $a$ is almost constant and $b$ decreases linearly with $f$.

To sum up, the modified power number can be linked with the modified Froude number and the filling ratio depending on the value of the cohesion (Eqs. (17) and (18)).

if $c<0.3 \mathrm{kPa} \rightarrow N_{p M}=(62 f-14) \cdot F_{r M}^{-1}$

if $c>0.6 \mathrm{kPa} \rightarrow N_{p M}=6 \cdot F_{r M}^{-0.52 f-0.92}$

This study of filling ratio has been undertaken with only one powder of each kind: semolina for free flowing and lactose for more cohesive. It should be extended to more powders to get a better reliability. Eqs. (17) and (18) allow the determination of the power numbers, and in turn power consumptions in the Triaxe ${ }^{\circledR}$ blender, at least in the gyrational speed range that is proper to a nearly bijective $P$ vs $u_{c h}$ relationship, and without performing many pilot scales experiments. The lab-scale measured cohesion of the powder and the filling ratio employed in the process are the only additional parameters to know.

\section{Conclusion}

The aims of this study were to determine the differences between free flowing powders and cohesive powders during a blending operation, and to correlate the power with process geometrical dimensions, operating parameters (agitation speed, filling ratio) and a powder property (cohesion).

A detailed analysis of the power consumption while a powder is stirred by the blender reveals two kinds of behavior, one for free flowing powders through a linear increase of the power with the agitation

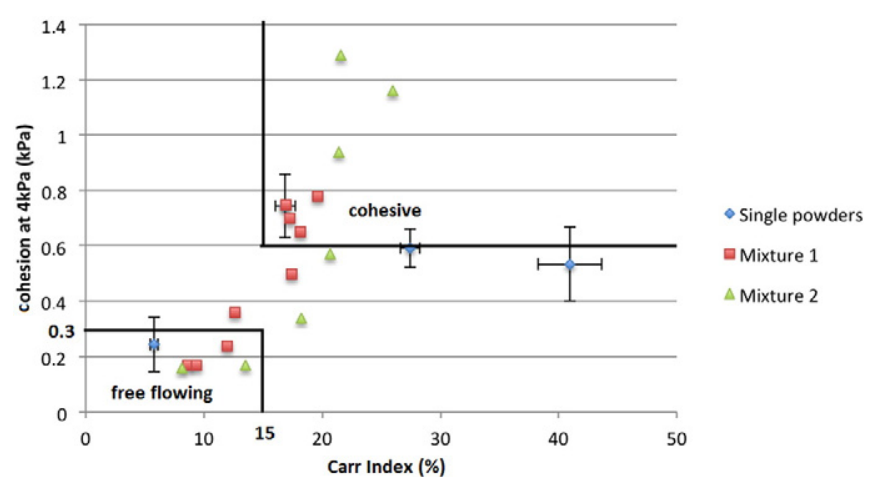

Fig. 16. Flow behavior of the powders studied according to Carr Indexes and cohesion.

speed, and one for cohesive powders where the power consumption is smaller and the gyration motion plays an important role to transmit the power into the whole powder bed.

Thanks to the Carr Index and the cohesion, two rheological behaviors can be distinguished: free flowing if the cohesion is smaller than $0.3 \mathrm{kPa}$ and cohesive if it is greater than $0.6 \mathrm{kPa}$. Coefficients $a$ and $b$ of the correlation $N_{p M}=a \cdot F_{r M}^{b}$ can be estimated depending on this classification. For free flowing powders $b=-1$, as demonstrated by André et al. in a previous study on the Triaxe ${ }^{\circledR}$ mixer [17] and $a$ coefficient is found to increase linearly with the filling ratio. Concerning cohesive powders, $a=6$ and the biggest filling ratios lead to a linear decrease in $b$ coefficient. With the knowledge of the powder cohesion value and of the apparent filling ratio inside the mixer tank, the power that is needed to stir the powder can be estimated. This is of high value for industrial applications since it limits the number of experiments to perform at full scale.

Nevertheless, there are limitations in this study: some powders demonstrate an unexpected behavior, like fine lactose, which is suspected to create agglomerates that in turn improve its flow inside the blender. Some powders cannot be classified easily with the comparison between cohesion and Carr Index, like talc, potentially because the platelets-shape particles result in a cohesion that is smaller than expected when the powder is sheared.

As a perspective to this work, a four bladed transparent cylindrical mixer, without gyration motion, has been set up to study directly the impact of the powder properties and process parameters on the different flow regimes induced by rotation. Investigating the flow involved in a bladed mixer is an essential step to create a model able to describe and predict what is happening in a complex planetary blender like the Triaxe®. This model will be based on a Markov chain analysis, as its ability to model powder flow has already been proved in many studies [26].
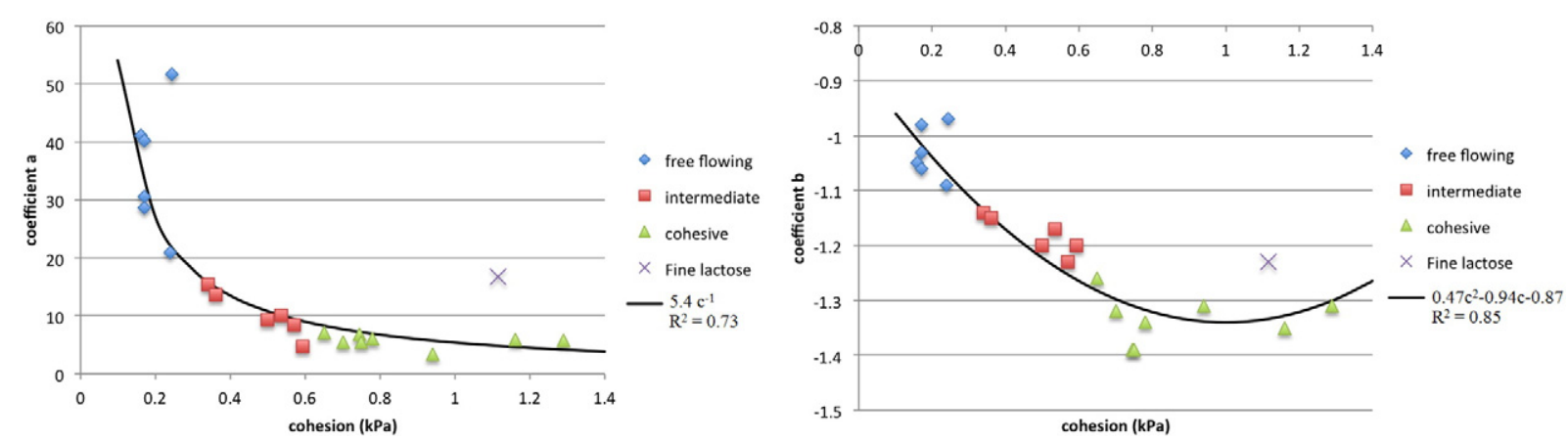

Fig. 15. Impact of powder cohesion on $a$ (left) and $b$ (right) coefficients for all powders and mixtures investigated (30 kg in Triaxe). 

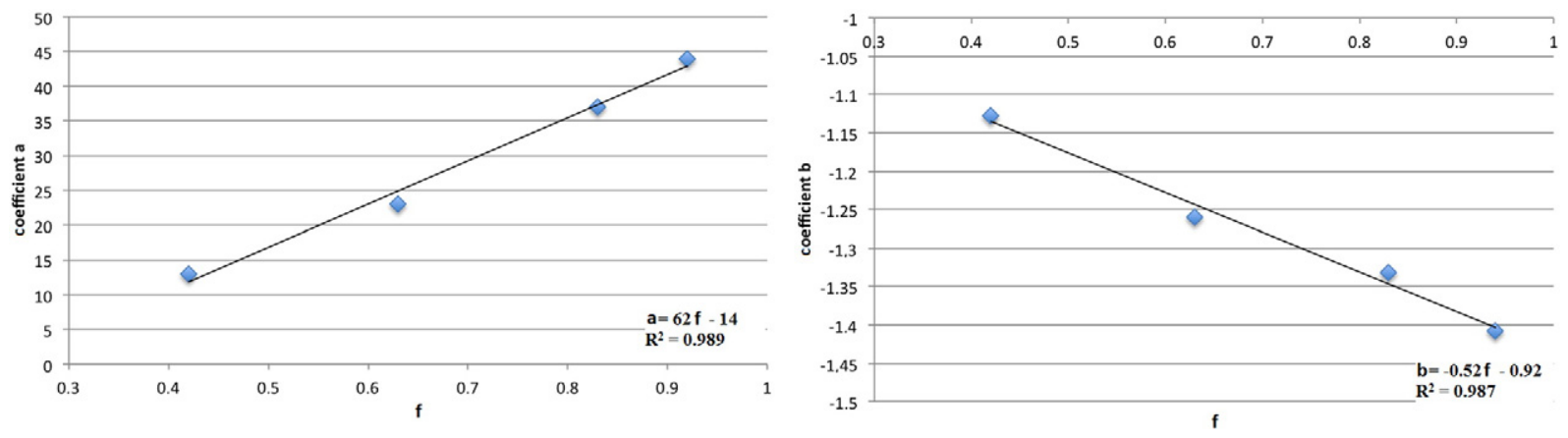

Fig. 17. Coefficient $a$ of semolina with $b=-1$ (left) and coefficient $b$ of lactose with $a=6$ (right) depending on the filling ratio.

\section{Nomenclature}

\begin{tabular}{lll}
\hline$\rho_{b}$ & bulk density & {$\left[\mathrm{kg} \cdot \mathrm{m}^{-3}\right]$} \\
$\rho_{t}$ & tapped density & {$\left[\mathrm{kg} \cdot \mathrm{m}^{-3}\right]$} \\
$\rho_{p}$ & true density & {$\left[\mathrm{kg} \cdot \mathrm{m}^{-3}\right]$} \\
$\Omega_{r a}$ & blade axis angular rotational speed & {$\left[\mathrm{rev} \cdot \mathrm{s}^{-1}\right]$} \\
$\Omega_{g a}$ & blade axis angular gyrational speed & {$\left[\mathrm{rev} \cdot \mathrm{s}^{-1}\right]$} \\
$\omega_{g e}$ & motor gyrational speed & {$\left[\mathrm{rad} \cdot \mathrm{s}^{-1}\right]$} \\
$\omega_{\rho e}$ & motor rotational speed & {$\left[\mathrm{rad} \cdot \mathrm{s}^{-1}\right]$} \\
$\omega_{r a}$ & blade axis rotational speed & {$\left[\mathrm{rad} \cdot \mathrm{s}^{-1}\right]$} \\
$\omega_{g a}$ & blade axis gyrational speed & {$\left[\mathrm{rad} \cdot \mathrm{s}^{-1}\right]$} \\
$c$ & powder cohesion under $4 \mathrm{kPa}$ pre-shear & {$[\mathrm{Pa}]$} \\
$d_{50}$ & characteristic particle diameter & {$[\mathrm{m}]$} \\
$D$ & distance between two blade tips & {$[\mathrm{m}]$} \\
$d_{s}$ & diameter of Triaxe's spherical reducer & {$[\mathrm{m}]$} \\
$f$ & Triaxe's filling ratio & $\%$ \\
$I C$ & Carr Index & $\%$ \\
$P$ & power needed to stir powder in Triaxe & {$[\mathrm{W}]$} \\
$T_{g 0}$ & gyrational torque for empty tank & {$[\mathrm{N} \cdot \mathrm{m}]$} \\
$T_{g f}$ & gyrational torque for filled tank & {$[\mathrm{N} \cdot \mathrm{m}]$} \\
$T_{r 0}$ & rotational torque for empty tank & {$[\mathrm{N} \cdot \mathrm{m}]$} \\
$T_{r f}$ & rotational torque for filled tank & {$[\mathrm{N} \cdot \mathrm{m}]$} \\
$u_{c h}$ & impeller characteristic tip speed & {$[\mathrm{m} \cdot \mathrm{s}-1]$} \\
\hline
\end{tabular}

\section{Acknowledgements}

Many thanks to Laurent Devriendt and Manon Bru, respectively a technician and an internship student at RAPSODEE research center, for their contribution in powder characterization and stirring experiments.

\section{References}

[1] J. Bridgwater, Fundamental powder mixing mechanisms, Powder Technol. 15 (1976) 215-236, http://dx.doi.org/10.1016/0032-5910(76)80051-4.

[2] M.E. Aulton (Ed.), Pharmaceutics: The Science of Dosage Form Design, Churchill Livingstone, Edinburgh etc., Royaume-Uni, 2002.

[3] J.M. Valverde Millán, Fluidization of Fine Powders, Springer Netherlands, Dordrecht, 2013 http://link.springer.com/10.1007/978-94-007-5587-1 (accessed February 1, 2016).

[4] J. Nagy, Development and Control of Dust Explosions, CRC Press, 1983.

[5] A.W. Alexander, B. Chaudhuri, A. Faqih, F.J. Muzzio, C. Davies, M.S. Tomassone, Avalanching flow of cohesive powders, Powder Technol. 164 (2006) 13-21, http://dx.doi.org/10.1016/j.powtec.2006.01.017.

[6] J.R. Bourne, The Mixing of Powders, Pastes and Non-Newtonian Fluids, Institution of Chemical Engineers, 1964

[7] H. Li, J.J. McCarthy, Cohesive particle mixing and segregation under shear, Powder Technol. 164 (2006) 58-64, http://dx.doi.org/10.1016/j.powtec.2005.12.018.
[8] G. Reverdy, Contrôle éléctrique intégral de la fabrication des bétons hydrauliques, Rev. Gen. Routes 381 (1963) 125-126.

[9] B. Cazagliu, J. Legrand, Characterization of the granular-to-fluid state process during mixing by power evolution in a planetary concrete mixer, Chem. Eng. Sci. 63 (2008) 4617-4630, http://dx.doi.org/10.1016/j.ces.2008.06.001.

[10] J. Bagster, J. Bridgwater, The measurement of the force needed to move blades through a bed of cohesionless granules, Powder Technol. 1 (1967) 189-198, http://dx.doi.org/10.1016/0032-5910(67)80036-6.

[11] P.W. Bridgman, Dimensional analysis, by P.W. Bridgman., rev. ed., New Haven, http://hdl.handle.net/2027/mdp.490150001208821963.

[12] T.S. Makishima, Experimental study on the power requirements for agitating beds of solid particles, and proposal of a new model, J. Chem. Eng. Jpn 1 (1968) 168-174, http://dx.doi.org/10.1252/jcej.1.168.

[13] W. Entrop, Proc. European Conference on Mixing in the Chemical and Allied Industries, 1978 1-14.

[14] M. Sato, K. Miyanami, T. Yano, Power requirement of horizontal cylindrical mixer, J. Soc. Powder Technol. Jpn. 16 (1979) 3-7, http://dx.doi.org/10.4164/sptj.16.3.

[15] P.C. Knight, J.P.K. Seville, A.B. Wellm, T. Instone, Prediction of impeller torque in high shear powder mixers, Chem. Eng. Sci. 56 (2001) 4457-4471, http://dx.doi.org/10. 1016/S0009-2509(01)00114-2.

[16] C. André, J.F. Demeyre, C. Gatumel, H. Berthiaux, G. Delaplace, Dimensional analysis for planetary mixer homogenizing granular materials: mixing time and froude numbers, Chem. Eng. J. 198-199 (2012) 771-778.

[17] C. André, J.F. Demeyre, C. Gatumel, H. Berthiaux, G. Delaplace, Derivation of dimensionless relationships for the agitation of powders of different flow behaviours in a planetary mixer, Powder Technol. 256 (2014) 33-38, http://dx.doi.org/10.1016/j. powtec.2014.02.002.

[18] I. Gijón-Arreortúa, A. Tecante, Mixing time and power consumption during blending of cohesive food powders with a horizontal helical double-ribbon impeller, J. Food Eng. 149 (2015) 144-152, http://dx.doi.org/10.1016/j.jfoodeng.2014.10.013.

[19] R. Carr, Evaluating Flow Properties of Solids, 72, 1965 163-168.

[20] M. Leturia, M. Benali, S. Lagarde, I. Ronga, K. Saleh, Characterization of flow properties of cohesive powders: a comparative study of traditional and new testing methods, Powder Technol. 253 (2014) 406-423, http://dx.doi.org/10.1016/j. powtec.2013.11.045.

[21] A.W. Jenike, Gravity Flow of Bulk Solids, Salt Lake City, http://catalog.hathitrust.org/ Record/1007116301961 (accessed February 1, 2016).

[22] J.W. Carson, H. Wilms, Development of an international standard for shear testing, Powder Technol. 167 (2006) 1-9, http://dx.doi.org/10.1016/j.powtec.2006.04.005.

[23] G. Calvert, M. Ghadiri, M. Dyson, P. Kippax, F. McNeil-Watson, The flowability and aerodynamic dispersion of cohesive powders, Powder Technol. 240 (2013) 88-94, http://dx.doi.org/10.1016/j.powtec.2012.07.003.

[24] J.-F. Demeyre, Caractérisation de l'homogénéité de mélange de poudres et de l'agitation en mélangeur Triaxe ${ }^{\circledR}$, INPT, Toulouse, 2007 http://www.theses.fr/ 2007INPT034G (accessed February 1, 2016).

[25] G. Delaplace, R.K. Thakar, L. Bouvier, C. André, C. Torrez, Dimensional analysis for planetary mixer: modified power and Reynolds numbers, Chem. Eng. Sci. 62 (2007) 1142-1447.

[26] H. Berthiaux, V. Mizonov, Applications of Markov chains in particulate process engineering: a review, Can. J. Chem. Eng. 82 (2004) 1143-1168, http://dx.doi.org/10. $1002 /$ cjce.5450820602. 